\title{
Diets high in resistant starch and arabinoxylan modulate digestion processes and SCFA pool size in the large intestine and faecal microbial composition in pigs
}

\author{
Tina S. Nielsen ${ }^{1 *}$, Helle N. Lærke ${ }^{1}$, Peter K. Theil ${ }^{1}$, Jens F. Sørensen ${ }^{2}$, Markku Saarinen ${ }^{3}$, \\ Sofia Forssten ${ }^{3}$ and Knud E. Bach Knudsen ${ }^{1}$ \\ ${ }^{1}$ Department of Animal Science, Faculty of Science and Technology, Aarbus University, Blichers Allé 20, PO Box 50, \\ DK-8830 Tjele, Denmark \\ ${ }^{2}$ DuPont Industrial Biosciences, Edwin Rabrs Vej 38, DK-8220 Brabrand, Denmark \\ ${ }^{3}$ DuPont Nutrition and Health, Sokeritehtaantie 20, 02460 Kantvik, Finland
}

(Submitted 11 April 2014 - Final revision received 8 August 2014 - Accepted 20 August 2014 - First published online 20 October 2014)

\section{Abstract}

The effects of a high level of dietary fibre (DF) either as arabinoxylan (AX) or resistant starch (RS) on digestion processes, SCFA concentration and pool size in various intestinal segments and on the microbial composition in the faeces were studied in a model experiment with pigs. A total of thirty female pigs (body weight 63.1 (SEM 4.4) kg) were fed a low-DF, high-fat Western-style control diet (WSD), an AX-rich diet (AXD) or a RS-rich diet (RSD) for 3 weeks. Diet significantly affected the digestibility of DM, protein, fat, NSP and NSP components, and the arabinose:xylose ratio, as well as the disappearance of NSP and AX in the large intestine. RS was mainly digested in the caecum. AX was digested at a slower rate than RS. The digesta from AXD-fed pigs passed from the ileum to the distal colon more than twice as fast as those from WSD-fed pigs, with those from RSD-fed pigs being intermediate $(P<0 \cdot 001)$. AXD feeding resulted in a higher number of Faecalibacterium prausnitzii, Roseburia intestinalis, Blautia coccoides-Eubacterium rectale, Bifidobacterium spp. and Lactobacillus spp. in the faeces sampled at week 3 of the experimental period $(P<0 \cdot 05)$. In the caecum, proximal and mid colon, AXD feeding resulted in a 3- to 5-fold higher pool size of butyrate compared with WSD feeding, with the RSD being intermediate $(P<0 \cdot 001)$. In conclusion, the RSD and AXD differently affected digestion processes compared with the WSD, and the AXD most efficiently shifted the microbial composition towards butyrogenic species in the faeces and increased the large-intestinal butyrate pool size.

Key words: Arabinoxylan: Resistant starch: SCFA: Microbial composition: Pigs

A dietary pattern characterised by a high intake of fat, proteins from meat, refined carbohydrates and a low intake of nondigestible carbohydrates (dietary fibre, DF), as is typical for many people in affluent societies, is regarded as a significant risk factor for the development of colorectal cancers ${ }^{(1)}$ and for the onset and relapse of inflammatory bowel disease ${ }^{(2)}$. The low content of DF in a Western-style diet (WSD) is a limiting factor for maintaining a viable and diverse microbial community and for the production of small organic molecules such as SCFA, primarily acetate, propionate and butyrate ${ }^{(3)}$. Especially, butyrate has been suggested to be a main modulator of colonic health and function ${ }^{(4)}$, and SCFA has been mostly associated with protection against chemically and dietary-induced colorectal carcinogenic pre-stages in rats ${ }^{(5,6)}$ Apart from being the preferred energy source for colonic epithelial cells and the major regulator of cell proliferation and differentiation ${ }^{(3)}$, butyrate has been shown to exert important actions related to cellular homeostasis, such as anti-inflammatory $^{(7)}$, antioxidant ${ }^{(8)}$ and anti-carcinogenic ${ }^{(9)}$ functions. Many of these effects have been related to its action as a histone deacetylase inhibitor ${ }^{(10,11)}$.

Identification of DF types that can increase the production of colonic butyrate is therefore of great interest. Resistant starch (RS), which is included in the definition of $\mathrm{DF}^{(12)}$, covers a diverse range of starches that are not enzymatically degraded in the small intestine of human subjects, but,

Abbreviations: AX, arabinoxylan; AXD, arabinoxylan diet; AXOS, arabinoxylan oligosaccharides; BCFA, branched-chain fatty acids; Co1, proximal one-third of the colon; $\mathrm{CO} 2$, mid one-third of the colon; Co3, distal one-third of the colon; DF, dietary fibre; DMSO, dimethyl sulphoxide; HAM-RS2, type 2 resistant

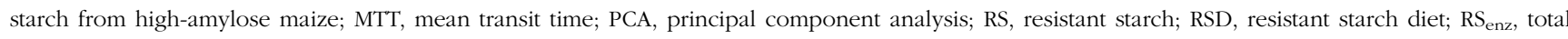
content of resistant starch; Si3, distal one-third of the small intestine; WSD, Western-style diet.

*Corresponding author: T. S. Nielsen, email tinas.nielsen@agrsci.dk 
instead, fermented in the large intestine, favouring butyrate production $^{(13)}$. Recently, a diet high in RS has been shown to modulate microbial composition and increase colonic butyrate concentration in the proximal part of the colon in pigs ${ }^{(14)}$. As most micro-organisms prefer to ferment carbohydrate over protein, saccharolytic fermentation occurs predominantly in the proximal colon. Proteolytic fermentation, resulting in the production of potentially harmful metabolites such as $\mathrm{NH}_{3}$, S-containing compounds, indoles and phenols, takes place in the more distal colon where the amount of fermentable carbohydrates is diminished ${ }^{(15)}$, and this coincides with the fact that many colonic diseases appear in the distal colon ${ }^{(16)}$. A more distal fermentation of dietary carbohydrates is therefore desirable ${ }^{(17)}$, and the challenge is to have a non-digestible carbohydrate substrate delivered to the distal colon for increased microbial fermentation and butyrate production. Arabinoxylans (AX) are another interesting type of DF in this respect. Their structure consists of a backbone of xylose units substituted with arabinose monomers ${ }^{(18)}$. These may further be linked to other compounds such as glucuronic acid and ferulic acid, leading to covalent ester bonding between the carboxyl groups of uronic acids and the hydroxyl groups of $\mathrm{AX}$, as well as the formation of diferulic acid bridges between the adjacent $\mathrm{AX}$ chains ${ }^{(18)}$; altogether, fermentation requires a broad spectrum of enzymes and thereby $\mathrm{AX}$ are potential candidates to be a slowly fermentable fibre source $^{(19)}$ and a substrate for butyrate production in the distal colon.

It is hypothesised that both RS and AX stimulate butyrate production in the large intestine. In the present study, we investigated the effects of diets enriched in DF as mainly RS or AX compared with a Western-style type of diet high in fat, refined carbohydrates and low in DF on nutrient digestibility, concentration and pool size of fermentation products in various segments of the intestinal tract and faecal microbial composition in pigs as a model for humans. Pigs are shown to be a suitable model for human metabolism in food research ${ }^{(20)}$, and the anatomy and physiology of the gastrointestinal tract in pigs are regarded as comparable to humans ${ }^{(21)}$.

\section{Materials and methods}

\section{Experimental diets}

The three dietary treatments were a WSD, an AX diet (AXD) or a RS diet (RSD). The WSD was designed to mimic the diet of many people in affluent societies characterised by being high in sugar, refined grains and saturated fat and low in DF (6\%). The AXD and RSD were formulated to contain high DF (17\%) mainly in the form of AX derived from enzyme-treated wheat bran and rye flakes or type 2 RS from high-amylose maize (HAM-RS2; HI-MAIZE260 ${ }^{\circledR}$, Ingredion Incorporated) and raw potato starch. Before its incorporation into the AXD, wheat bran was treated with xylanases and cellulases to increase the content of AX oligosaccharides (AXOS). AXOS have been shown to have a stimulating effect on intestinal butyrate production in human subjects compared with wheat bran without in situ-produced AXOS $^{(22)}$. Rye flakes were chosen as the main AX supplier because rye is an important cereal in a typical Danish diet, and earlier studies with rye-based diets (whole-grain rye plus rye bran) have shown high butyrate production ${ }^{(23)}$. The sources of RS were chosen to ensure comparability to RS ingredients applied in a human dietary intervention study within this project frame. HAM-RS2 was the main RS source in human diets since it is resistant to cooking and can be incorporated into many foods. RS from raw potato starch is not resistant to cooking and was therefore included in a minor proportion. Overall, the AX and RS ingredients were chosen to simulate the complexity of human diets. The three diets were designed to provide the same amount of energy from fat (30\%) and protein (17\%), while the proportion of energy originating from DF was 3.5\% in the WSD and $9 \%$ in the RSD and AXD (see Tables 1 and 2 for dietary ingredients and chemical composition, respectively).

The enzyme-treated wheat bran was produced by DuPont Industrial Biosciences, Danisco $\mathrm{A} / \mathrm{S}$ as follows: commercial wheat bran obtained from Lantmännen Cerealia was suspended in water (bran:water ratio 20:80, w/w) in a closed container with a stirring device. DuPont Grindamyl PowerBake 950 (500 parts per million) and DuPont GC220 (5000 parts per million) were added to the suspension, and the temperature was increased to $50^{\circ} \mathrm{C}$ and stirring was applied. When the temperature reached $50^{\circ} \mathrm{C}$, incubation was continued for $3 \mathrm{~h}$. After $3 \mathrm{~h}$, the temperature was increased to $95^{\circ} \mathrm{C}$ and maintained at $95^{\circ} \mathrm{C}$ for $10 \mathrm{~min}$ to inactivate enzyme activity. Wheat bran was cooled to ambient temperature and dried using a pilot spray dryer and packed in paper bags. The concentration of oligosaccharides in the enzyme-treated wheat bran was $54 \mathrm{~g} / \mathrm{kg}$ DM. Commercially available rye flakes was purchased from Lantmännen Cerealia and potato starch from KMC and HAM-RS2 from Ingredion Incorporated. $\mathrm{Cr}_{2} \mathrm{O}_{3}$ $(0.3 \%)$ was included in all diets to calculate the apparent

Table 1. Ingredients of the Western-style diet (WSD), the resistant starch diet (RSD) and the arabinoxylan diet (AXD)

\begin{tabular}{lccc}
\hline & \multicolumn{3}{c}{ Diet } \\
\cline { 2 - 4 } & WSD & RSD & AXD \\
\hline Ingredients (g/kg, as-fed basis) & 568 & 455 & - \\
$\quad$ Standard white wheat flour & - & - & 655 \\
Rye flakes & - & - & 80 \\
Enzyme-treated wheat bran & - & 56 & - \\
Raw potato starch & - & 168 & - \\
HI-MAIZE260 & & & \\
Lard & 96 & 89 & 80 \\
Soyabean oil & 32 & 30 & 27 \\
Sugar & 100 & - & - \\
Lacprodan 87 (83\% whey protein) $\dagger$ & 131 & 129 & 85 \\
Vitacel WF600 (73\% cellulose) & 40 & 40 & 40 \\
Vitamin-mineral mixture§ & 30 & 30 & 30 \\
Chromic oxide & 3 & 3 & 3 \\
\hline
\end{tabular}

*Ingredion Incorporated.

† Arla Foods Ingredients Amba, Viby J.

$\ddagger J$. Rettenmaier and Söhne $\mathrm{GmbH}$.

§Supplied per $\mathrm{kg}$ diet: $18.9 \mathrm{mg}$ retinol (vitamin A); $0.15 \mathrm{mg}$ cholecalciferol (vitamin $D_{3}$ ); $1038 \mathrm{mg} \alpha$-tocopherol (vitamin $\mathrm{E}$ ); $31.5 \mathrm{mg}$ vitamin $\mathrm{K} ; 31.5 \mathrm{mg}$ vitamin $B_{1} ; 31.5 \mathrm{mg}$ vitamin $B_{2} ; 157.5 \mathrm{mg} D$-pantothenic acid (vitamin $\mathrm{B}_{5}$ ); $315 \mathrm{mg}$ niacin (vitamin $B_{3}$ ); $0.79 \mathrm{mg}$ biotin (vitamin $B_{7}$ ); $0.315 \mathrm{mg}$ vitamin $B_{12} ; 47.3 \mathrm{mg}$ vitamin $B_{6} ; 1260 \mathrm{mg} \mathrm{Fe} ; 225 \mathrm{mg}$ copper sulphate; $630 \mathrm{mg}$ Mn (VA Vit SL/US Anti; Vilomix). 
Table 2. Chemical composition and particle size distribution of the Western-style diet (WSD), the resistant starch diet (RSD) and the arabinoxylan diet (AXD)

\begin{tabular}{|c|c|c|c|}
\hline & \multicolumn{3}{|c|}{ Diet } \\
\hline & WSD & RSD & AXD \\
\hline \multicolumn{4}{|l|}{ Chemical composition (g/kg DM) } \\
\hline DM (g/kg, as-fed basis) & 915 & 903 & 891 \\
\hline Protein $(\mathrm{N} \times 6.25)$ & 207 & 191 & 154 \\
\hline Fat & 152 & 150 & 135 \\
\hline Ash & 37 & 34 & 51 \\
\hline \multicolumn{4}{|l|}{ Digestible carbohydrates } \\
\hline Available sugars & 113 & 3 & 22 \\
\hline Fructose & $0 \cdot 1$ & 0 & 1.8 \\
\hline Glucose & 0.1 & 0 & 3.1 \\
\hline Sucrose & 112 & $3 \cdot 1$ & 17.5 \\
\hline Starch & 422 & 470 & 420 \\
\hline \multicolumn{4}{|l|}{ Non-digestible carbohydrates } \\
\hline Total NSP (soluble NSP) & $58(11)$ & $55(8)$ & $144(33)$ \\
\hline Cellulose & 29 & 34 & 37 \\
\hline$\beta$-Glucan (soluble $\beta$-glucan) & $1(<1)$ & $1(<1)$ & $16(3)$ \\
\hline AX (soluble AX) & $18(6)$ & $15(4)$ & $72(22)$ \\
\hline $\mathrm{RS}_{\mathrm{enz}}{ }^{*}$ & 6 & $113 \dagger$ & 8 \\
\hline $\mathrm{RS}_{\text {DMSO }} \neq$ & 1 & 64 & 5 \\
\hline Fructans & 0 & 3 & 22 \\
\hline AXOS & 2 & 2 & 7 \\
\hline Arabinose:xylose & 0.36 & 0.33 & 0.55 \\
\hline Klason lignin & 6 & 13 & 15 \\
\hline Total non-digestible $\mathrm{CHO}$ & 64 & 173 & 181 \\
\hline Total dietary fibre\| & 72 & 186 & 196 \\
\hline Gross energy (MJ/kg DM) & $19 \cdot 7$ & $20 \cdot 3$ & $19 \cdot 3$ \\
\hline \multicolumn{4}{|l|}{ Particle size distribution (\%) } \\
\hline$>2 \mathrm{~mm}$ & 1.5 & 1.0 & 0.0 \\
\hline$>1 \mathrm{~mm}$ & $5 \cdot 1$ & $6 \cdot 8$ & $13 \cdot 1$ \\
\hline$<1 \mathrm{~mm}$ & 93.8 & 92.2 & 86.5 \\
\hline
\end{tabular}

AX, arabinoxylan; RS, resistant starch; DMSO, dimethyl sulphoxide; AXOS, arabinoxylan oligosaccharides; $\mathrm{CHO}$, carbohydrate.

${ }^{*}$ RS was determined by the Megazyme assay (Megazyme International).

$\dagger 76 \%$ of the total RS originated from type 2 resistant starch from high-amylose maize and $24 \%$ from raw potato starch calculated using data on RS content from the suppliers of the ingredients.

$\ddagger$ Determined using the NSP procedure with the addition of DMSO to disperse RS.

$\S$ Calculated as: total NSP + fructans + RS.

$\|$ Calculated as: total NSP + fructans + RS + lignin + AXOS.

I $50 \mathrm{~g}$ of sample size for each diet.

digestibility of DM, nutrients and NSP components. The AXD containing whole-rye flakes was ground through a hammer mill fitted with a $3.5 \mathrm{~mm}$ screen. The analysis of the particle size (Retsch AS 200 Control; Retsch $\mathrm{GmbH}$ ) for each diet is shown in Table 2. All the three diets qualified as finely ground $^{(24)}$, and small differences in particle size distribution were not considered as a factor that affected the apparent digestibility of nutrients and NSP components and the mean transit time (MTT) of the digesta. Samples of the experimental diets were collected after production at Aarhus University's own feed production unit and stored at $-20^{\circ} \mathrm{C}$ until analysis.

\section{Animals and feeding}

The care and housing of animals used in the present study were in compliance with Danish laws and regulations for the humane care and use of animals in research (The Danish Ministry of Justice, Animal Testing Act, Consolidation Act no. 1306 of 23 November 2007), and performed under the licence obtained from the Danish Animal Experimentation
Inspectorate, Ministry of Food, Agriculture and Fisheries. The health of the animals was monitored, and no serious illness was observed.

A total of thirty female pigs (body weight 63.1 (SEM 4.4) kg) recruited from the swine herd at the Department of Animal Science, Aarhus University, Foulum, were fed one of three diets (WSD, AXD or RSD) for an experimental period of 3 weeks. The experiment was conducted in two blocks with five animals per treatment in each block. Pigs were housed individually in pens $(1.5 \times 2.4 \mathrm{~m})$ without manipulative material (straw), with access to water ad libitum and allowed to adapt to the pen for $5 \mathrm{~d}$ before the experimental period.

Daily feed allowance for the pigs treated with the RSD and AXD was $2.7 \%$ of average body weight $(75 \mathrm{~kg})$, whereas those treated with the WSD were fed $2 \cdot 44 \%$ of body weight to ensure similar daily amounts of net energy among the three dietary treatments. Pigs were fed manually three times daily at $10.00,15.00$ and 20.00 hours $(33.3 \%$ of total ration at each meal) to mimic the human meal pattern. Very few feed leftovers were observed; however, any feed leftovers were registered before the morning feeding and weighed to calculate feed intake. The amount of feed supplied to pigs $1.5 \mathrm{~h}$ before slaughter was adjusted slightly to provide equal amounts $(300 \mathrm{~g})$ of digestible carbohydrates regardless of diet, in order to obtain as much consistency as possible with the study design developed by Ingerslev et al. ${ }^{(25)}$ using the same diets as described here, in a catheterised pig model. A fresh faecal sample was obtained $3 \mathrm{~d}$ before slaughter and stored at $-20^{\circ} \mathrm{C}$ until analysis. Body weight was recorded weekly.

\section{Slaughter and sample collection}

Pigs were stunned using a captive bolt pistol and subsequently bled from the jugular vein. The abdominal cavity was opened and the gastrointestinal tract was ligated at the oesophagus and rectum and removed from the carcass. The length of the small intestine was measured and divided into three parts of equal lengths. The content of the distal third (Si3) was collected for analysis, and the entire empty small intestine was weighed. Caecal (Cae) digesta was weighed, and the large intestine (colon) was isolated and the length determined. The positions at 25, 50 and $75 \%$ of the length of the colon (descending) were termed $\mathrm{Co} 1, \mathrm{Co} 2$ and $\mathrm{Co} 3$, respectively. Digesta from the colon segments were weighed and the entire empty colon was weighed. $\mathrm{pH}$ was measured in the $\mathrm{Si} 3$, Cae, Co1, Co2 and Co3 digesta, and samples of the digesta from these intestinal segments were stored at $-20^{\circ} \mathrm{C}$ until further analysis.

\section{Analytical methods}

All chemical analyses on diets were performed in duplicate on freeze-dried material. DM content was determined by drying the samples at $103^{\circ} \mathrm{C}$ to constant weight, and ash was analysed according to the AOAC method (923.03; AOAC) ${ }^{(26)}$. N was measured by Dumas ${ }^{(27)}$ and protein calculated as $\mathrm{N} \times 6.25$. Gross energy was analysed on a 6300 Automatic Isoperibol 
Calorimeter System (Parr Instruments). Fat was determined using the Stoldt procedure ${ }^{(28)}$. Dietary contents of sugars (glucose, fructose and sucrose) and fructans were analysed as described by Larsson \& Bengtsson ${ }^{(29)}$. Starch and NSP were analysed essentially as described by Bach Knudsen ${ }^{(30)}$ except that acid hydrolysis was performed in $2 \mathrm{M}-\mathrm{H}_{2} \mathrm{SO}_{4}$ for $1 \mathrm{~h}$ instead of $1 \mathrm{M}-\mathrm{H}_{2} \mathrm{SO}_{4}$ for $2 \mathrm{~h}$. AX was calculated as the sum of the arabinose and xylose residues of the NSP procedure mentioned above. AXOS were calculated from arabinose and xylose residues not precipitating in $80 \%$ ethanol when analysing the samples by direct acid hydrolysis of the NSP fraction without prior starch removal and alcohol precipitation and subtracting the values for AX after starch removal and alcohol precipitation ${ }^{(31)}$. When the RSD and the individual RSD ingredients were analysed for NSP by the enzymaticchemical method ${ }^{(30)}$, it was found that part of the RS in the RSD and in the HAM-RS2 ingredient was not degraded. Therefore, NSP in the RSD and in the digesta of pigs fed the RSD was subsequently analysed with the addition of dimethyl sulphoxide (DMSO) to disperse $\mathrm{RS}^{(32)}$. The RS estimated with this method is designated as $\mathrm{RS}_{\mathrm{DMSO}}$. All the three diets and digesta from RSD-fed pigs were analysed for total RS content with a commercially available kit (Megazyme International Ireland), designated as $\mathrm{RS}_{\text {enz }}$. Klason lignin was measured as the sulphuric acid-insoluble residue as described by Theander \& $\AA$ man ${ }^{(33)}$. $\beta$-Glucan was analysed by the enzymatic-colorimetric method of McCleary \& Glennie-Holmes ${ }^{(34)}$. Chromic oxide was determined colorimetrically using a Lambda 900 spectrophotometer (Perkin-Elmer $\mathrm{GmbH}$ ), after oxidation to chromate with sodium peroxide following the procedure of Schürch et al. $^{(35)}$.

Digesta and faecal samples were analysed for the content of SCFA by GC (HP-6890 Series Gas Chromatograph; Hewlett Packard) using an HP-5 column $(30 \mathrm{~m} \times 0.32 \mathrm{~mm} \times 0.25 \mu \mathrm{m})$ with 5\% phenylpolysiloxane and 95\% demethylpolysiloxane and a flame ionisation detector, after subjecting the samples to an acid-base treatment followed by diethyl ether extraction and derivatisation, as described by Jensen et al. ${ }^{(36)}$.

\section{Faecal microbial composition}

DNA from each sample was extracted and purified with a commercial kit MagMAX $^{\mathrm{TM}}$ Total Nucleic Acid Isolation Kit; Applied Biosystems), and DNA concentration was determined by a Nanodrop ND-1000 Full-Spectrum UV/Vis Spectrophotometer (NanoDrop Technologies). Quantitative PCR assays were performed in a total volume of $25 \mu$ l containing $1 \times$ Power SYBR Green Master Mix (Applied Biosystems), $200 \mathrm{~nm}$ of each primer for Lactobacillus spp. ${ }^{(37)}, 250 \mathrm{~nm}$ of each primer for Faecalibacterium prausnitzii ${ }^{(38)}$, and $300 \mathrm{~nm}$ of each primer for Roseburia spp. ${ }^{(39)}$ and the Blautia coccoidesEubacterium rectale group ${ }^{(38)}$. The $25 \mu \mathrm{l}$ PCR mix for the Bifidobacterium spp. ${ }^{(39)}$ assay contained $1 \times$ TaqMan Master Mix (Applied Biosystems), $300 \mathrm{~nm}$ of forward and reverse primers and $200 \mathrm{~nm}$ of the minor groove binding probe (with a non-fluorescent black hole quencher). All quantitative PCR contained $1 \mathrm{ng}$ of template DNA. The amplification and detection of DNA were performed with the ABI-PRISM 7500 sequencing detection system (Applied Biosystems). For standard curves, 10-fold dilution series ranging between $10 \mathrm{pg}$ and $1 \mathrm{ng}$ were included in the quantitative PCR assays from the following target species: Bifidobacterium adolescentis DSM 20083; Ruminococcus productus DSM 2950; F. prausnitzii ATCC 27768; Lactobacillus acidophilus ATCC 700396; Roseburia intestinalis DSM 14610. For the determination of DNA, triplicate samples were used and the mean quantity was expressed as $\log _{10}$ genomes per $g$ of sample (wet weight), taking into account the size and the $16 \mathrm{~S}$ ribosomal DNA copy number of the standard species genome.

\section{Calculations}

The apparent digestibility coefficients of nutrients and NSP sugars in the digesta from intestinal segments were calculated relative to $\mathrm{Cr}_{2} \mathrm{O}_{3}$ concentration, according to the following equation:

$$
\text { Digestibility of } X=1-\frac{\mathrm{Cr}_{2} \mathrm{O}_{3(\text { Diet })} \times X_{(\text {Dig })}}{\mathrm{Cr}_{2} \mathrm{O}_{3(\text { Dig })} \times X_{(\text {Diet })}},
$$

where $X_{(\text {Diet })}$ and $X_{\text {(Dig) }}$ are the concentrations of the component determined in the diet and digesta, respectively, and $\mathrm{Cr}_{2} \mathrm{O}_{3 \text { (Diet) }}$ and $\mathrm{Cr}_{2} \mathrm{O}_{3 \text { (Dig) }}$ are the concentrations of chromic oxide in the diet and digesta, respectively.

MTT in the large-intestinal segments was calculated as follows:

$$
\mathrm{MTT}=\frac{\mathrm{Cr}_{2} \mathrm{O}_{3(\mathrm{GI})} \times 24}{\mathrm{Cr}_{2} \mathrm{O}_{3(\text { day })}},
$$

where $\mathrm{Cr}_{2} \mathrm{O}_{3(\mathrm{GI})}$ is the concentration of $\mathrm{Cr}_{2} \mathrm{O}_{3}$ in the digesta and $\mathrm{Cr}_{2} \mathrm{O}_{3 \text { (day) }}$ is the daily intake of $\mathrm{Cr}_{2} \mathrm{O}_{3}$.

The pool size of SCFA in the digesta was determined by calculating the daily amount of wet undigested DM passing through the intestinal segment multiplied by the concentration of SCFA in the wet luminal content of the segment. The largeintestinal $\mathrm{N}$ pool size was determined by calculating the daily amount of undigested DM passing through the intestinal segment multiplied by the $\mathrm{N}$ content of DM in the segment.

\section{Statistical analysis}

In the present study, two types of analysis on data were carried out. The first type of analysis was accomplished using the MIXED procedure of SAS (SAS Institute, Inc.) followed by adjustment for multiple comparisons by the Tukey-Kramer post hoc test. The effects of diet on the intestinal segment apparent digestibility of DM, macronutrients, NSP components and on the pool of fermentation metabolites in the digesta were analysed using the following normal mixed model:

$$
X_{(i j k l)}=\mu+\alpha_{(i)}+\beta_{(j)}+\gamma_{(k)}+\alpha \gamma_{(i k)}+\nu_{(l)}+\varepsilon_{(i j k l)},
$$

were $\alpha_{(i)}$ is the diet ( $i=\mathrm{WSD}, \mathrm{RSD}$ or $\left.\mathrm{AXD}\right) ; \beta_{(j)}$ is the random effect of block ( $j=1$ or 2$) ; \gamma_{(k)}$ is the intestinal segment $(k=\mathrm{Si} 3$, Cae, $\mathrm{Co} 1, \mathrm{Co} 2$ or $\mathrm{Co} 3) ; \alpha \gamma_{(i k)}$ is the interaction between diet and intestinal segment; $\nu_{(t)}$ is the random component related to the pig $(l=1,2, \ldots, 30)$. Pig was 
included as a random component to account for repeated measurements within pigs. The covariance structure for repeated measures across the gut segments was modelled using variance components and the residual error component is defined as $\boldsymbol{\varepsilon}_{(i j k l)}$. Levels of significance was reported as being significant when $P<0.05$. The random effects and residuals were assumed to be normally distributed and independent, and their expectations were assumed to be zero.

The second type of analysis compared the effects of dietary treatments on pig weight gain, intake of nutrients, intestinal tract characteristics at slaughter (length and weight of intestinal segments, digesta $\mathrm{pH}$ ) and microbial composition in the faeces. This model was accomplished by a simple ANOVAbased on the model:

$$
X_{(i j)}=\mu+\alpha_{(i)}+\beta_{(j)}+\alpha \beta_{(i j)}+\varepsilon_{(i j)},
$$

where $\alpha_{(i)}$ is the diet ( $i=\mathrm{WSD}$, RSD or $\left.\mathrm{AXD}\right) ; \beta_{(j)}$ is the random effect of the block ( $j=1$ or 2); $\alpha \beta_{(i j)}$ is the interaction between diet and block, and $\varepsilon_{(i j)}$ denotes the residual error under the same assumptions as in the first statistical model.

Principal component analysis (PCA) with evenly spread 7-fold partial cross-validation after mean centring and unit variance scaling was performed using Evince 2.5.5 software (UmBio $\mathrm{AB}$ ) to detect distributions and separations among the dietary treatments.

\section{Results}

\section{Diets, intake of nutrients and intestinal segments} at slaughter

The three diets were formulated to provide equal amounts of fat, protein and energy, of which the RSD and AXD provided equal amounts but different types of DF. This was successfully accomplished except for protein (Table 2). The protein content of the AXD was $40-50 \mathrm{~g} / \mathrm{kg}$ DM lower than the RSD and WSD, which was due to a higher than expected protein content of wheat flour incorporated into the RSD and WSD compared with our database value. The content of total DF was increased 2.7-fold from the WSD to the RSD and AXD. The RSD had a higher RS content $>100 \mathrm{~g} / \mathrm{kg}$ DM compared with the WSD and AXD. The AXD had a higher AX content $>50 \mathrm{~g} / \mathrm{kg}$ DM compared with the WSD and RSD. The $\mathrm{RS}_{\text {enz }}$ content in the WSD and AXD was negligible; however, it amounted to $113 \mathrm{~g} / \mathrm{kg}$ DM in the RSD. The RS $\mathrm{DMSO}_{\text {content }}$ in the RSD was $64 \mathrm{~g} / \mathrm{kg} \mathrm{DM}$, thereby constituting $56 \%$ of the $\mathrm{RS}_{\text {enz }}$. The arabinose:xylose ratio, which is a simple indicator of AX structure, was similar in both the WSD (0.36) and RSD (0.33), but approximately $67 \%$ higher in the AXD. AXOS constituted $2 \mathrm{~g} / \mathrm{kg}$ DM in the WSD and RSD and $7 \mathrm{~g} / \mathrm{kg} \mathrm{DM}$ in the AXD.

Due to a slightly higher daily feed allowance, the RSD- and AXD-fed pigs consumed approximately $100 \mathrm{~g} / \mathrm{d}$ more DM than the WSD-fed pigs (Table 3), whereas the WSD- and RSD-fed pigs consumed $69-75 \mathrm{~g} / \mathrm{d}$ more $(P<0.001)$ protein than AXD-fed pigs due to the higher content of protein in their diets. The RSD- and AXD-fed pigs consumed 2.8-fold more $(P<0.001)$ DF compared with the WSD-fed pigs. The average
Table 3. Intake of nutrients and energy, weight gain, weight of the intestinal segments and digesta and $\mathrm{pH}$ in the digesta at slaughter for pigs fed the Western-style diet (WSD), the resistant starch diet (RSD) or the arabinoxylan diet (AXD) for 3 weeks

(Least-squares mean values with their standard errors, $n 10$ per group)

\begin{tabular}{|c|c|c|c|c|c|}
\hline & \multicolumn{3}{|c|}{ Diet } & \multirow[b]{2}{*}{ SEM } & \multirow[b]{2}{*}{$P$} \\
\hline & WSD & RSD & AXD & & \\
\hline \multicolumn{6}{|l|}{ Intake $(g / d)$} \\
\hline DM & $1705^{\mathrm{b}}$ & $1818^{a}$ & $1808^{a}$ & $4 \cdot 0$ & $<0.001$ \\
\hline Protein & $353^{a}$ & $347^{\mathrm{a}}$ & $278^{b}$ & 0.8 & $<0.001$ \\
\hline Fat & $259^{b}$ & $273^{\mathrm{a}}$ & $244^{c}$ & 0.6 & $<0.001$ \\
\hline $\mathrm{CHO}$ & $1011^{b}$ & $1058^{a}$ & $1060^{a}$ & $2 \cdot 4$ & $<0.001$ \\
\hline Total dietary fibre & $119^{\mathrm{C}}$ & $349^{a}$ & $342^{\mathrm{b}}$ & 0.8 & $<0.001$ \\
\hline Gross energy (MJ/d) & $33 \cdot 6^{\mathrm{c}}$ & $36 \cdot 9^{\mathrm{a}}$ & $34.9^{\mathrm{b}}$ & 0.1 & $<0.001$ \\
\hline Weight gain $(\mathrm{g} / \mathrm{d})$ & $616^{\mathrm{b}}$ & $606^{\mathrm{b}}$ & $720^{a}$ & 33.5 & 0.045 \\
\hline \multicolumn{6}{|l|}{ Weight $(\mathrm{g})$} \\
\hline $\mathrm{Cae}$ & 121 & 140 & 135 & $6 \cdot 0$ & 0.10 \\
\hline Entire colon & $944^{\mathrm{a}}$ & $1193^{\mathrm{b}}$ & $1118^{\mathrm{b}}$ & 29 & $<0.001$ \\
\hline \multicolumn{6}{|l|}{ Weight digesta (g) } \\
\hline $\mathrm{Cae}$ & $146^{\mathrm{a}}$ & $229^{\mathrm{a}, \mathrm{b}}$ & $286^{\mathrm{b}}$ & 36 & 0.03 \\
\hline $\begin{array}{l}\text { Entire colon } \\
\mathrm{pH} \text { digesta }\end{array}$ & $1090^{b}$ & $1687^{\mathrm{a}}$ & $1790^{\mathrm{a}}$ & 106 & $<0.01$ \\
\hline Cae & $6 \cdot 82^{a}$ & $6 \cdot 31^{\mathrm{b}}$ & $6 \cdot 54^{a, b}$ & 0.14 & 0.02 \\
\hline $\mathrm{Co1}$ & $6.57^{a}$ & $6 \cdot 13^{\mathrm{b}}$ & $6 \cdot 13^{\mathrm{b}}$ & $0 \cdot 13$ & 0.01 \\
\hline Co2 & $6 \cdot 48^{\mathrm{a}}$ & $6 \cdot 37^{\mathrm{a}, \mathrm{b}}$ & $6 \cdot 14^{\mathrm{b}}$ & 0.09 & 0.04 \\
\hline $\mathrm{Co} 3$ & 6.44 & $6 \cdot 19$ & $6 \cdot 34$ & 0.24 & 0.25 \\
\hline
\end{tabular}

$\mathrm{CHO}$, carbohydrate; Cae, caecum; Co1, proximal one-third of the colon; Co2, mid one-third of the colon; $\mathrm{Co}$, distal one-third of the colon.

a,b,c Mean values within a row with unlike superscript letters were significantly different $(P<0.05)$

daily gain was approximately $100 \mathrm{~g}$ higher $(P<0.05)$ for the AXD-fed pigs than for the WSD- and RSD-fed pigs. The high fibre level in the RSD and AXD increased the weight of the entire colon by $18-26 \%(P<0.001)$ and the weight of the colonic digesta by 54-64\% $(P<0 \cdot 01)$ compared with the WSD (Table 3). The weight of the caecum was unaffected by the diet, but the weight of the caecal digesta was significantly increased by the AXD compared with the WSD. RSD feeding resulted in a lower $(P=0.02)$ luminal $\mathrm{pH}$ than the WSD in the caecum; however, in the Co1, feeding of both the fibre diets resulted in a significantly lower luminal $\mathrm{pH}$ than the WSD. In the Co2, this pH-lowering effect was only significant for the AXD. No effect of diet on luminal $\mathrm{pH}$ was observed in the distal colon.

\section{Nutrient apparent digestibility, disappearance and transit time}

Table 4 shows the apparent digestibility (termed digestibility) of DM, nutrients and selected NSP components and the arabinose:xylose ratio in large-intestinal segments. DM was digested to a higher $(P<0 \cdot 001)$ degree in all intestinal segments of WSD-fed pigs than in those of RSD- and AXD-fed pigs, with the feeding of the AXD resulting in the lowest digestibility of DM in all segments. The digestibility of protein was $14-21 \%$ lower $(P<0 \cdot 001)$ in AXD-fed pigs throughout the large intestine than in WSD-fed pigs, whereas the RSD-fed pigs showed intermediate protein digestibility. Consequently, $20 v$. $6 \%$ of ingested protein was still undigested in the distal colon of AXD- and WSD-fed pigs, respectively. Fat was digested less 
Table 4. Digestibility of DM, nutrients and NSP components and the ratio of arabinose:xylose in the different segments of the large intestine of pigs fed the Western-style diet (WSD), the resistant starch diet (RSD) or the arabinoxylan diet (AXD) for 3 weeks (Least-squares mean values with their standard errors, $n 10$ per treatment)

\begin{tabular}{|c|c|c|c|c|c|c|c|c|}
\hline \multirow[b]{2}{*}{ Digestibility } & \multirow[b]{2}{*}{ Segment } & \multicolumn{3}{|c|}{ Diet } & \multirow[b]{2}{*}{ SEM } & \multicolumn{3}{|c|}{$P$} \\
\hline & & WSD & RSD & AXD & & Diet & Segment & Diet $\times$ segment \\
\hline \multirow[t]{4}{*}{ DM } & $\mathrm{Cae}$ & $0.87^{\mathrm{a}}$ & $0.81^{b}$ & $0.78^{\mathrm{c}}$ & \multirow[t]{4}{*}{0.007} & \multirow[t]{4}{*}{$<0.001$} & \multirow[t]{4}{*}{$<0.001$} & \multirow[t]{4}{*}{$<0.001$} \\
\hline & Co1 & $0.91^{\mathrm{a}}$ & $0.85^{\mathrm{b}}$ & $0.83^{C}$ & & & & \\
\hline & Co2 & $0.92^{\mathrm{a}}$ & $0.87^{b}$ & $0.84^{\mathrm{c}}$ & & & & \\
\hline & Co3 & $0.92^{a}$ & $0.88^{\mathrm{b}}$ & $0.85^{\mathrm{C}}$ & & & & \\
\hline \multirow[t]{4}{*}{ Protein $(\mathrm{N} \times 6.25)$} & $\mathrm{Cae}$ & $0.92^{\mathrm{a}}$ & $0.84^{b}$ & $0.71^{\mathrm{c}}$ & \multirow[t]{4}{*}{0.007} & \multirow[t]{4}{*}{$<0.001$} & \multirow[t]{4}{*}{$<0.001$} & \multirow[t]{4}{*}{$<0.001$} \\
\hline & Co1 & $0.93^{\mathrm{a}}$ & $0.86^{\mathrm{b}}$ & $0.76^{c}$ & & & & \\
\hline & $\mathrm{Co} 2$ & $0.94^{\mathrm{a}}$ & $0.87^{b}$ & $0.78^{c}$ & & & & \\
\hline & Co3 & $0.94^{\mathrm{a}}$ & $0.88^{b}$ & $0.80^{C}$ & & & & \\
\hline \multirow[t]{4}{*}{ Fat } & $\mathrm{Cae}$ & $0.93^{\mathrm{a}}$ & $0.89^{\mathrm{a}}$ & $0.84^{\mathrm{b}}$ & \multirow[t]{4}{*}{0.01} & \multirow[t]{4}{*}{$<0.001$} & \multirow[t]{4}{*}{$<0.01$} & \multirow[t]{4}{*}{0.58} \\
\hline & Co1 & $0.92^{\mathrm{a}}$ & $0.90^{\mathrm{a}}$ & $0.84^{\mathrm{b}}$ & & & & \\
\hline & $\mathrm{Co} 2$ & $0.92^{\mathrm{a}}$ & $0.89^{\mathrm{a}}$ & $0.83^{b}$ & & & & \\
\hline & $\mathrm{Co} 3$ & $0.91^{a}$ & $0.89^{a}$ & $0.83^{b}$ & & & & \\
\hline \multirow[t]{4}{*}{ Starch } & $\mathrm{Cae}$ & $1.00^{\mathrm{a}}$ & $0.98^{\mathrm{b}}$ & $0.99^{\mathrm{a}, \mathrm{b}}$ & \multirow[t]{4}{*}{0.003} & \multirow[t]{4}{*}{0.007} & \multirow[t]{4}{*}{$<0.001$} & \multirow[t]{4}{*}{$<0.001$} \\
\hline & Co1 & $1.00^{\mathrm{a}}$ & $0.98^{\mathrm{b}}$ & $0.99^{a, b}$ & & & & \\
\hline & $\mathrm{Co} 2$ & 1.00 & 0.99 & 0.99 & & & & \\
\hline & Co3 & 1.00 & 1.00 & 1.00 & & & & \\
\hline \multirow[t]{4}{*}{ Total NSP } & Cae & $0.28^{\mathrm{b}}$ & $0.08^{c}$ & $0.47^{a}$ & \multirow{4}{*}{0.05} & \multirow{4}{*}{$<0.001$} & $<0.001$ & $<0.001$ \\
\hline & Co1 & $0.43^{\mathrm{a}}$ & $0.24^{b}$ & $0.60^{\mathrm{a}}$ & & & & \\
\hline & $\mathrm{Co} 2$ & $0.60^{\mathrm{a}}$ & $0.32^{b}$ & $0.64^{a}$ & & & & \\
\hline & Co3 & $0.68^{\mathrm{a}}$ & $0.43^{\mathrm{b}}$ & $0.68^{\mathrm{a}}$ & & & & \\
\hline $\mathrm{RS}_{\mathrm{enz}}$ & $\mathrm{Cae}$ & - & 0.82 & - & 0.03 & - & $<0.001$ & - \\
\hline & Co1 & - & 0.89 & - & & & & \\
\hline & Co2 & - & 0.95 & - & & & & \\
\hline & $\mathrm{Co} 3$ & _- & 0.97 & - & & & & \\
\hline Arabinoxylan & $\mathrm{Cae}$ & $0 \cdot 41^{a, b}$ & $0.27^{b}$ & $0.52^{a}$ & 0.04 & $<0.001$ & $<0.001$ & $<0.001$ \\
\hline & Co1 & $0.62^{\mathrm{a}}$ & $0.41^{\mathrm{b}}$ & $0.69^{a}$ & & & & \\
\hline & $\mathrm{Co} 2$ & $0.69^{a}$ & $0.47^{b}$ & $0.66^{\mathrm{a}}$ & & & & \\
\hline & Co3 & $0.74^{\mathrm{a}}$ & $0.57^{b}$ & $0.67^{\mathrm{a}, \mathrm{b}}$ & & & & \\
\hline Arabinose:xylose ratio & $\mathrm{Cae}$ & $0 \cdot 18^{\mathrm{b}}$ & $0 \cdot 16^{b}$ & $0.74^{\mathrm{a}}$ & 0.02 & $<0.001$ & $<0.001$ & $<0.001$ \\
\hline & Co1 & $0.16^{\mathrm{b}}$ & $0.15^{b}$ & $0.76^{\mathrm{a}}$ & & & & \\
\hline & $\mathrm{Co} 2$ & $0.24^{b}$ & $0.16^{\mathrm{b}}$ & $0.91^{a}$ & & & & \\
\hline & Co3 & $0 \cdot 25^{\mathrm{b}}$ & $0.23^{\mathrm{b}}$ & $1.00^{\mathrm{a}}$ & & & & \\
\hline
\end{tabular}

Cae, caecum; Co1, proximal one-third of the colon; Co2, mid one-third of the colon; Co3, distal one-third of the colon; RS enz $_{\text {, total }}$ content of resistant starch.

a,b,c Mean values within a row with unlike superscript letters were significantly different between the diets $(P<0.05)$.

efficiently $(P<0.001)$ in all gut segments of AXD-fed pigs than in those of WSD- and RSD-fed pigs, while no differences were observed between the WSD and RSD in any of the segments. The digestibility of starch was not affected by the diet. Only $8 \%$ of NSP was digested in the caecum of RSDfed pigs, whereas it was $47 \%$ in that of AXD-fed pigs, with intermediate digestibility being observed in WSD-fed pigs. Also, in the three colon segments, the digestibility of NSP was $19-32 \%$ lower $(P<0.001)$ in RSD-fed pigs than in WSDand AXD-fed pigs, with the latter two showing comparable NSP digestibilities. RS was only detected in the digesta from RSD-fed pigs. RS was mainly digested in the caecum and only $3 \%$ of RS was still undigested in the distal colon (Table 4$)$. The content of total RS $\left(\mathrm{RS}_{\text {enz }}\right)$, expressed as the percentage of digesta DM, in large-intestinal segments of pigs fed the RSD and the proportion of $\mathrm{RS}_{\mathrm{enz}}$ constituted by $\mathrm{RS}_{\mathrm{DMSO}}$ are shown in Fig. 1 . In the caecal digesta, $\mathrm{RS}_{\mathrm{DMSO}}$ constituted approximately $65 \%$ of $\mathrm{RS}_{\text {enz }}$. In the colon segments, $\mathrm{RS}_{\mathrm{DMSO}}$ constituted $70-100 \%$ of $\mathrm{RS}_{\mathrm{enz}}$. For comparison, $\mathrm{RS}_{\text {DMSO }}$ constituted $56 \%$ of the $\mathrm{RS}_{\text {enz }}$ in the RSD. In general, $\mathrm{AX}$ was digested at a slower rate than RS irrespective of the dietary treatments. There was no difference in the digestibility of AX between the WSD and AXD in any of the gut segments, whereas the digestibility of AX in RSD-fed pigs was somewhat lower $(P<0.001)$ throughout the large intestine. The arabinose:xylose ratio was 0.6 to 0.75 higher $(P<0.001)$ in all the gut segments of AXD-fed pigs than in those of RSD- and WSD-fed pigs. Low concentrations of AXOS could be detected in the Si3 digesta of AXD-fed pigs, but not in those of WSD- and RSD-fed pigs. AXOS was only present at trace levels in the caecal digesta of AXD-, WSDand RSD-fed pigs (data not shown).

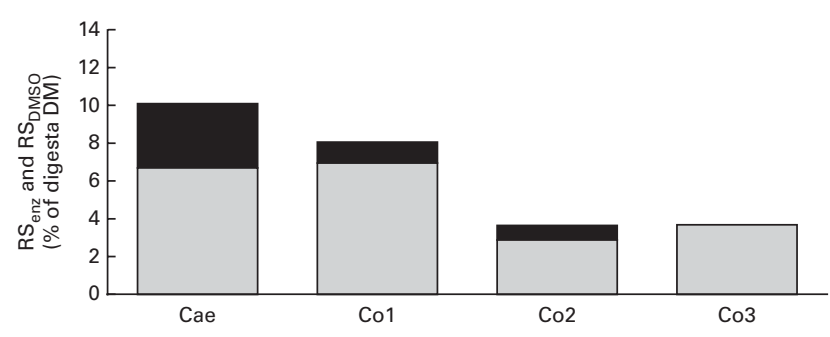

Fig. 1. Total content of resistant starch $\left(\mathrm{RS}_{\mathrm{enz}}, \boldsymbol{\square}\right)$ and proportion of $\mathrm{RS}_{\mathrm{enz}}$ comprising $\mathrm{RS}_{\text {dimethylsulphoxide }}\left(\mathrm{RS}_{\mathrm{DMSO}}, \square\right)$ in percentage of digesta $\mathrm{DM}$ sampled from the caecum (Cae), proximal one-third of the colon (Co1), mid one-third of the colon (Co2) and distal one-third of the colon (Co3) of RS diet-fed pigs $(n 10)$. Mean values are shown. 
Table 5. Amounts ${ }^{\star}$ of the disappearance of the selected nutrients from the caecum and colon and nitrogen pool size in the caecum and colon of pigs fed the Western-style diet (WSD), the resistant starch diet (RSD) or the arabinoxylan diet (AXD) for 3 weeks

(Least-squares mean values with their standard errors, $n 10$ per treatment)

\begin{tabular}{|c|c|c|c|c|c|c|c|c|}
\hline \multirow[b]{2}{*}{ Disappearance $(\mathrm{g} / \mathrm{d})$} & \multirow[b]{2}{*}{ Segment } & \multicolumn{3}{|c|}{ Diet } & \multirow[b]{2}{*}{ SEM } & \multicolumn{3}{|c|}{$P$} \\
\hline & & WSD & RSD & AXD & & Diet & Segment & Diet $\times$ segment \\
\hline Fat & $\begin{array}{l}\text { Caecum } \\
\text { Colon }\end{array}$ & $\begin{array}{c}9.8 \\
-1.9\end{array}$ & $\begin{array}{r}6.0 \\
-1.4\end{array}$ & $\begin{array}{c}4.3 \\
-1.0\end{array}$ & 2.5 & 0.67 & $<0.001$ & 0.47 \\
\hline Protein $(\mathrm{N} \times 6.25)$ & $\begin{array}{l}\text { Caecum } \\
\text { Colon }\end{array}$ & $\begin{array}{l}45 \cdot 8 \\
17 \cdot 9\end{array}$ & $\begin{array}{l}29 \cdot 2 \\
14 \cdot 4\end{array}$ & $\begin{array}{l}33 \cdot 8 \\
29 \cdot 3\end{array}$ & $6 \cdot 2$ & 0.21 & 0.004 & 0.22 \\
\hline tNSP & $\begin{array}{l}\text { Caecum } \\
\text { Colon }\end{array}$ & $\begin{array}{c}21 \cdot 3^{\mathrm{b}} \\
45 \cdot 7\end{array}$ & $\begin{array}{c}9 \cdot 7^{b} \\
33 \cdot 2\end{array}$ & $\begin{array}{c}104.5^{\mathrm{a}} \\
55 \cdot 0\end{array}$ & $5 \cdot 4$ & $<0.001$ & 0.91 & $<0.001$ \\
\hline $\mathrm{RS}_{\mathrm{enz}}$ & $\begin{array}{l}\text { Caecum } \\
\text { Colon }\end{array}$ & $\begin{array}{l}- \\
-\end{array}$ & $\begin{array}{l}73.3 \\
30.7\end{array}$ & $\begin{array}{l}- \\
-\end{array}$ & $7 \cdot 2$ & - & 0.006 & - \\
\hline$A X$ & $\begin{array}{l}\text { Caecum } \\
\text { Colon }\end{array}$ & $\begin{array}{c}8 \cdot 2^{\mathrm{b}} \\
10 \cdot 7^{\mathrm{b}}\end{array}$ & $\begin{array}{l}7 \cdot 0^{\mathrm{b}} \\
7.5^{\mathrm{b}}\end{array}$ & $\begin{array}{l}57 \cdot 4^{\mathrm{a}} \\
19 \cdot 4^{\mathrm{a}}\end{array}$ & 1.9 & $<0.001$ & $<0.001$ & $<0.001$ \\
\hline N pool size $(g / d)$ & $\begin{array}{l}\text { Caecum } \\
\text { Colon }\end{array}$ & $\begin{array}{c}4 \cdot 9^{\mathrm{c}} \\
18 \cdot 8^{\mathrm{c}}\end{array}$ & $\begin{array}{r}9.1^{\mathrm{b}} \\
20 \cdot 6^{\mathrm{b}}\end{array}$ & $\begin{array}{l}12 \cdot 7^{\mathrm{a}} \\
22 \cdot 4^{\mathrm{a}}\end{array}$ & 0.4 & $<0.001$ & $<0.001$ & $<0.001$ \\
\hline
\end{tabular}

tNSP, total NSP; $\mathrm{RS}_{\mathrm{enz}}$, total content of resistant starch; $\mathrm{AX}$, arabinoxylan.

a,b,c Mean values within a row with unlike superscript letters were significantly different between the diets $(P<0.05)$.

${ }^{*}$ Calculated using the average feed intake the day before slaughter and the apparent digestibility of fat, protein, $t N S P, \mathrm{RS}_{\text {enz }}, \mathrm{RS}_{\mathrm{DMSO}}$ and $\mathrm{AX}$.

The daily disappearance of selected dietary constituents and the $\mathrm{N}$ pool size in the caecum and colon are shown in Table 5. Diet did not affect the disappearance of fat and protein in the caecum and colon $(P=0.67$ and $P=0.21$, respectively); however, fat and protein disappeared to a significantly greater extent from the caecum than from the colon. The disappearance of total NSP was four to ten times higher $(P<0.001)$ in the caecum of AXD-fed pigs than in that of WSD- and RSD-fed pigs; however, there was no dietinduced differences in total NSP disappearance in the colon. There was a comparable amount of the disappearance of total NSP + total RS in the caecum and colon of AXD- and RSD-fed pigs (159v. $147 \mathrm{~g} / \mathrm{d}$, respectively). The disappearance of $\mathrm{RS}_{\text {enz }}$ was more than twice as high $(P=0.006)$ in the caecum as that in the colon of RSD-fed pigs. A similar amount of AX disappeared in the caecum and colon of WSD- and RSD-fed pigs. Given the three to four times higher content of AX in the AXD than that in the other diets, the disappearance of AX in both the caecum and colon was significantly higher in AXD-fed pigs and almost three times higher in the caecum. The daily $\mathrm{N}$ pool size was significantly higher in both the caecum and colon of AXD-fed pigs, intermediate in RSD-fed pigs and lowest in WSD-fed pigs. The feeding of the RSD and AXD resulted in a comparable but significantly lower MTT in the caecum and proximal part of the colon than the WSD (Table 6). In the $\mathrm{Co} 2$ and $\mathrm{Co} 3$, the MTT was highest in WSD-fed pigs, intermediate in RSD-fed pigs and lowest in AXD-fed pigs. The MTT from the Si3 to $\mathrm{CO} 3$ was less than half $(P<0.001)$ in AXD-fed pigs compared with WSD-fed pigs, with the MTT being intermediate in RSD-fed pigs.

\section{Concentration and pool size of SCFA in the digesta}

There was no diet-induced difference in the total SCFA concentration of the digesta except in the Co3 where a significantly higher concentration was observed in RSD-fed pigs $(107 \mathrm{mmol} / \mathrm{kg}$ wet digesta) than in WSD- or AXD-fed pigs (89 and $91 \mathrm{mmol} / \mathrm{kg}$ wet digesta, respectively). No differences between the diets were observed for acetate and propionate concentrations in any of the gut segments. Butyrate concentration was higher $(P<0.01)$ in the caecum (11 mmol/kg wet digesta) and Co1 $(16 \mathrm{mmol} / \mathrm{kg}$ wet digesta $)$ of AXD-fed pigs than in the caecum $(5 \mathrm{mmol} / \mathrm{kg}$ wet digesta) and $\mathrm{Co} 1(9 \mathrm{mmol} / \mathrm{kg}$ wet digesta) of WSD-fed pigs, with the concentration being intermediate in those of RSD-fed pigs and not significantly different from the other two groups. No differences in butyrate concentration were observed in the $\mathrm{Co} 2$ and $\mathrm{Co} 3$. The feeding of the WSD resulted in the significantly highest $(2.4 \mathrm{mmol} / \mathrm{kg}$ wet digesta $)$ and AXD in the significantly lowest concentration $(1.3 \mathrm{mmol} / \mathrm{kg}$ wet digesta) of branched-chain fatty acids (BCFA, sum of isobutyrate and isovalerate) in the caecum, whereas there were no diet-induced differences in the other intestinal segments.

Fig. 2 shows the pool size $(\mathrm{mmol} / \mathrm{d})$ of total and individual SCFA in various segments of the intestinal tract. The AXD increased $(P<0.05)$ the pool size of total SCFA by $100 \%$ or more compared with the WSD in all intestinal segments

Table 6. Mean transit time (h) in the intestinal segments of pigs fed either the Western-style diet (WSD), the resistant starch diet (RSD) or the arabinoxylan diet (AXD)

(Least-squares mean values with their standard errors, $n 10$ per treatment)

\begin{tabular}{lrrrrr}
\hline & \multicolumn{5}{c}{ Diet } \\
\cline { 2 - 4 } Intestinal segments & WSD & RSD & AXD & SEM & $P$ \\
\hline Cae & $6 \cdot 0^{\mathrm{a}}$ & $3 \cdot 3^{\mathrm{b}}$ & $2 \cdot 8^{\mathrm{b}}$ & 0.40 & $<0.001$ \\
Co1 & $4 \cdot 1^{\mathrm{a}}$ & $2 \cdot 0^{\mathrm{b}}$ & $2 \cdot 2^{\mathrm{b}}$ & 0.52 & 0.02 \\
Co2 & $2 \cdot 3^{\mathrm{a}}$ & $1 \cdot 3^{\mathrm{b}}$ & $0.4^{\mathrm{c}}$ & 0.31 & 0.001 \\
Co3 & $3 \cdot 6^{\mathrm{a}}$ & $2 \cdot 5^{\mathrm{b}}$ & $1 \cdot 2^{\mathrm{c}}$ & 0.42 & 0.002 \\
Si3-Co3 & $21 \cdot 0^{\mathrm{a}}$ & $12 \cdot 9^{\mathrm{b}}$ & $9 \cdot 3^{\mathrm{c}}$ & 0.95 & $<0.001$
\end{tabular}

Cae, caecum; Co1, proximal one-third of the colon; $\mathrm{Co} 2$, mid one-third of the colon; $\mathrm{Co3}$, distal one-third of the colon; $\mathrm{Si} 3$, distal one-third of the small intestine.

a,b,c Mean values within a row with unlike superscript letters were significantly different between the diets $(P<0.05)$. 

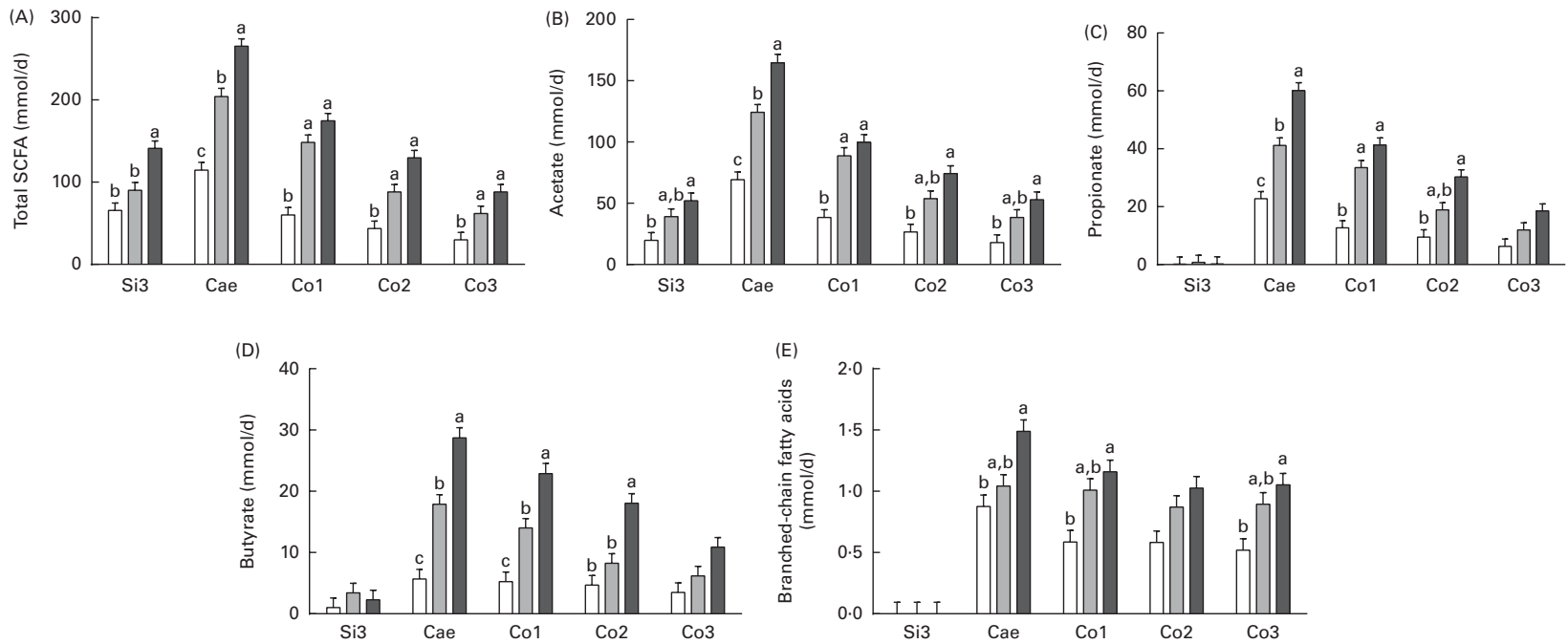

Fig. 2. Pool size of (A) total SCFA, (B) acetate, (C) propionate, (D) butyrate and (E) branched-chain fatty acids in the distal one-third of the small intestine (Si3), the caecum (Cae) and the proximal, mid and distal one-third of the colon (Co1, Co2 and Co3) of pigs fed one of the three different diets for 3 weeks. Values are least-squares means ( $n 10$ per diet), with their standard errors represented by vertical bars. ${ }^{a, b, c}$ Mean values with unlike letters were significantly different within the intestinal segments $(P<0.05)$. There was a significant effect for diet $((A-E) P<0.001)$ and the diet $\times$ segment interaction was significant $((A-D) P<0.001$ and (E) $P=0.006)$. $\square$, Western-style diet; $\square$, resistant starch diet; $\square$, arabinoxylan diet.

(Fig. 2(A)), with the RSD also increasing the pool size significantly, except in the Si3 and not to the same extent as the AXD in the caecum. A similar trend was observed for the pool size of acetate and propionate, with AXD feeding resulting in a significantly larger pool size than the WSD, except for propionate in the $\mathrm{Co} 3$, where an intermediate pool size was observed following the RSD. In the caecum, Co1 and Co2, AXD feeding resulted in a 3- to 5-fold larger $(P<0.001)$ pool size of butyrate compared with the WSD. In the caecum and Co1, the RSD also increased the butyrate pool significantly (2- to $2 \cdot 8$-fold) compared with the WSD. In the Co3, there was a non-significant increase in butyrate pool size by the AXD compared with the WSD. The pool size of BCFA was 70-100\% higher $(P<0.05)$ following the AXD in the caecum, Co1 and Co3 compared with the WSD, with an intermediate pool size being observed following the RSD without any difference from the other diets. In the entire large intestine, the AXD most efficiently increased the pool size of total SCFA, propionate and butyrate followed by the RSD and WSD (Table 7).

\section{Microbial composition in the faeces and principal component analysis}

Analyses of the microbial composition in the faeces sampled at week 3 of the experiment showed a significantly higher level of $F$. prausnitzii, $R$. intestinalis, B. coccoides-E. rectale, Bifidobacterium spp. and Lactobacillus spp. in AXD-fed pigs than that in the other two groups, although for Bifidobacterium spp., the RSD was not significantly different from either the AXD or the WSD (Fig. 3).

The results of PCA, which transforms a number of correlated variables into a small number of uncorrelated variables, on faecal microbial composition from week 3 of the experimental period and total and individual pool sizes of SCFA in intestinal segments are depicted in Fig. 4(A) and (B).
The first and the second principal components were responsible for $63.5 \%$ of the total variance, and there was a clear clustering between the three diets; high, intermediate and low intestinal SCFA production for the AXD, RSD and WSD, respectively. The individual variation was highest for RSDfed pigs, and from the PCA, one RSD-fed pig, in particular, was identified as an outlier (Fig. 4(A)).

\section{Discussion}

In the present study, we investigated the effect of increased amounts of DF from a low level (7\%) in a high-fat refinedcarbohydrate WSD to a high level (19\%), provided as either a RSD or AXD, on digestion processes, intestinal SCFA concentration and pool size and on faecal microbial composition. Of specific interest was the formation of butyrate due to its significant role in colonic health ${ }^{(4)}$ and as a key player in the microbial-mammalian metabolic axis ${ }^{(40)}$, providing a possible link between diet, intestinal microbiota and obesity-related metabolic diseases ${ }^{(41)}$. We provide evidence

Table 7. Pool size $(\mathrm{mmol} / \mathrm{d})$ of total and individual SCFA (branchedchain fatty acids; BCFA) in the large intestine (caecum + proximal onethird of the colon + mid one-third of the colon + distal one-third of the colon) in pigs fed either the Western-style diet (WSD), the resistant starch diet (RSD) or the arabinoxylan diet (AXD)

(Least-squares mean values with their standard errors)

\begin{tabular}{|c|c|c|c|c|c|}
\hline & \multicolumn{3}{|c|}{ Diet } & \multirow[b]{2}{*}{ SEM } & \multirow[b]{2}{*}{$P$} \\
\hline & WSD & RSD & AXD & & \\
\hline Total SCFA & $237^{c}$ & $512^{b}$ & $641^{a}$ & 31 & $<0.001$ \\
\hline Acetate & $152^{\mathrm{b}}$ & $320^{\mathrm{a}}$ & $384^{a}$ & 25 & $<0.001$ \\
\hline Propionate & $51^{c}$ & $109^{b}$ & $148^{\mathrm{a}}$ & 9 & $<0.001$ \\
\hline Butyrate & $19^{c}$ & $46^{\mathrm{b}}$ & $79^{a}$ & 5 & $<0.001$ \\
\hline BCFA & $2 \cdot 8^{\mathrm{b}}$ & $3 \cdot 8^{a, b}$ & $4 \cdot 4^{\mathrm{a}}$ & 0.4 & 0.01 \\
\hline
\end{tabular}

${ }^{a, b, c}$ Mean values within a row with unlike superscript letters were significantly different $(P<0.05)$. 


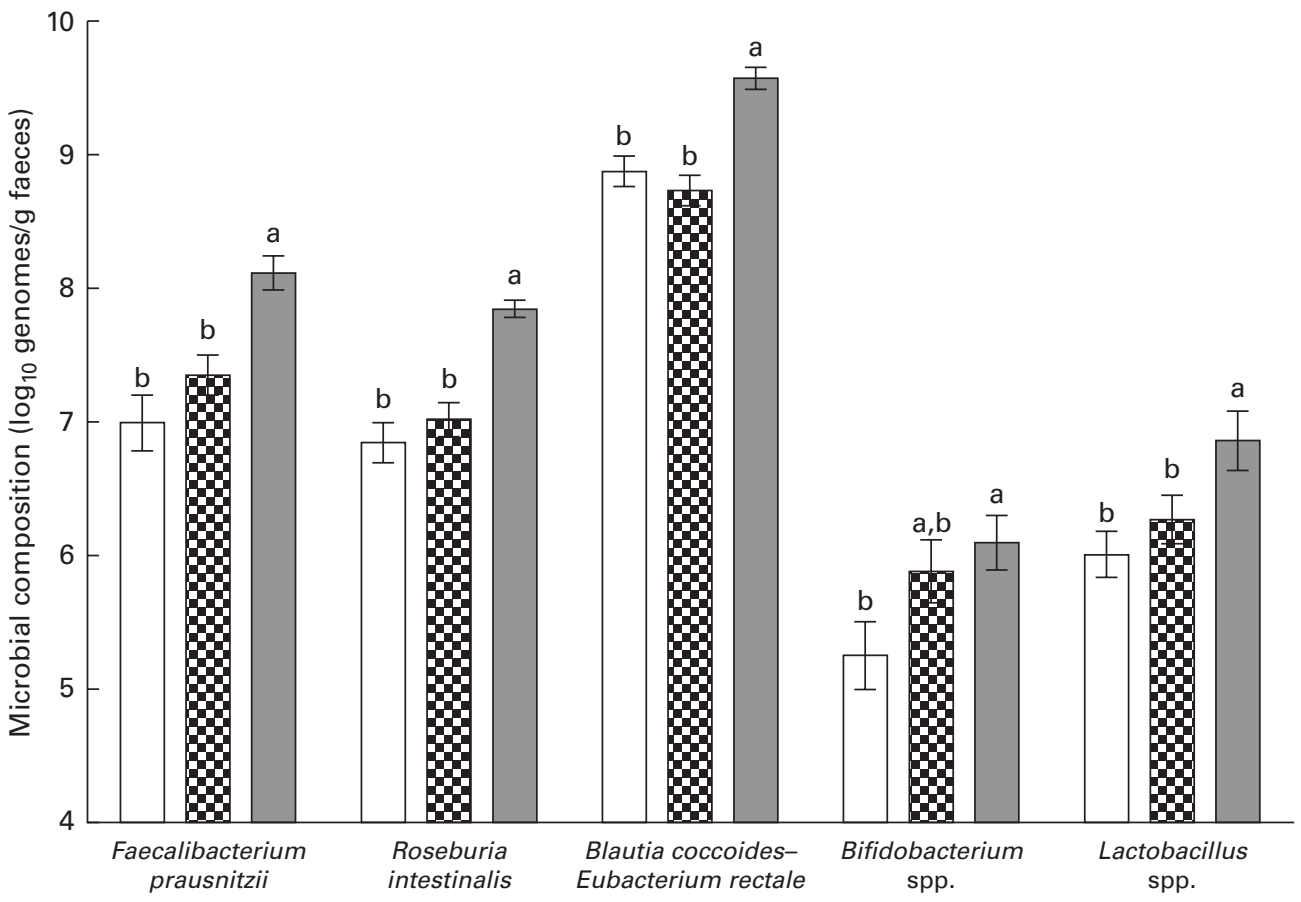

Fig. 3. Microbial composition in the faeces obtained at week 3 of the experimental period. Values are least-squares means ( $n 10$ per diet), with their standard errors represented by vertical bars. ${ }^{\text {a,b }}$ Mean values with unlike letters were significantly different within the bacterial species/group $(P<0.05)$. $\square$, Western-style diet; : resistant starch diet; $\square$, arabinoxylan diet.

that AX from rye flakes and enzyme-treated wheat bran is more efficient than RS from raw potato starch and HAM-RS2 in stimulating the number of butyrate-producing bacteria and in increasing the pool size of butyrate in the caecum, proximal and mid colon and thereby butyrate production. Bach Knudsen \& Lærke $^{(42)}$ showed a positive linear relation- ship between digested AX and net butyrate absorption in conscious catheterised pigs fed cereal-based bread diets varying in DF composition. This makes it plausible that the effects that we reported on especially butyrate pool size in the digesta are primarily due to AX components in the AXD, rather than other DF constituents in rye flakes and wheat bran, although
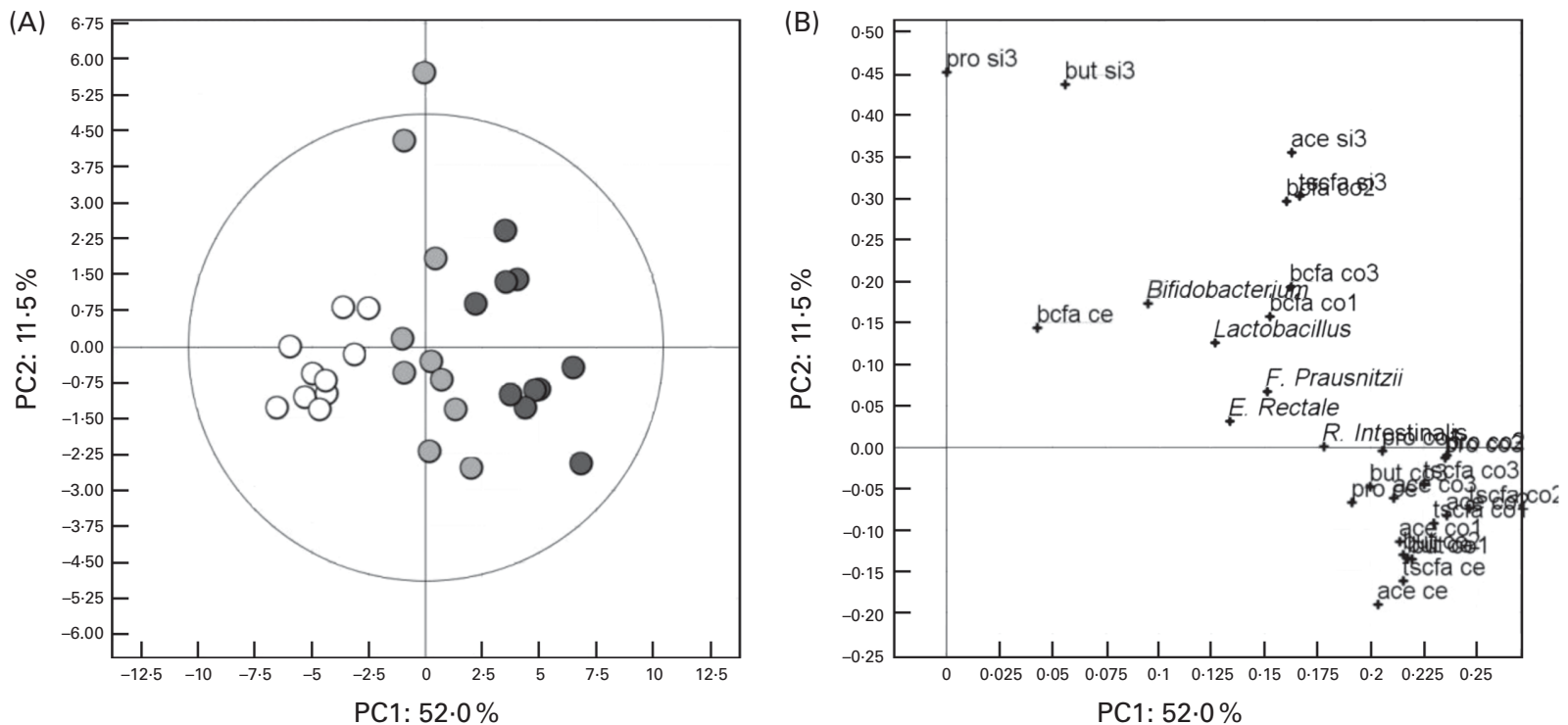

Fig. 4. Principal component (PC) analysis. (A) Score plot of faecal microbial composition and daily pool of total and individual SCFA in various segments of the intestines in pigs fed the Western-style diet $(O)$, the resistant starch diet $(O)$ or the arabinoxylan diet $(0)$ for 3 weeks. The circle marks the $95 \%$ Hotelling $\mathrm{T}^{2}$ control chart, showing possible outliers. (B) Projection of the parameters in the plane defined by the two first PC (loading plot). Si3, distal one-third of the small intestine; ce, caecum; co1, proximal one-third of the colon; co2, mid one-third of the colon; co3, distal one-third of the colon; tscfa, total scfa; ace, acetate; pro, propionate; but, butyrate; bcfa, branched-chain fatty acids (all pool size); F. prausnitzii, Faecalibacterium prausnitzii; E. rectale, Eubacterium rectale; R. intestinalis, Roseburia intestinalis. 
AX constitutes a smaller proportion of total DF in the AXD (40\%) than RS does in the RSD (61\%).

\section{Dietary fibre characteristics and effects on digestion processes}

The two high-DF diets provided equal amounts of DF, but with different chemical compositions and physical characteristics $^{(18,43)}$. The structure and degradability of AX depends on its origin ${ }^{(19,44,45)}$, and AX in the AXD was more substituted than that in the WSD and RSD based on the arabinose:xylose ratio of the diets. We found that $\mathrm{AX}$ in the AXD was more readily fermented already in the caecum and continued to be fermented along the large intestine, resulting in an increased substitution of AX in the undigested residue as also found by Glitso et al. ${ }^{(19)}$. In contrast, the structure of $\mathrm{AX}$ in the WSD and RSD was equally and hardly changed throughout the large intestine, although it should be noted that the total amount of AX in the WSD and RSD was one-quarter or less the level of AX in the AXD. This confirms that there is not necessarily a linear relationship between the arabinose:xylose ratio and $\mathrm{AX}$ degradability, since this also depends on, for example, the number of double substitutions ${ }^{(42)}$.

$\mathrm{RS}$ is defined as any starch or starch-derived material that escapes digestion and absorption in the upper digestive tract, and it comes in many forms with varying physical and organoleptic properties ${ }^{(46)}$. The high-amylose maize starch and raw potato starch in the RSD used in the present study belong to the RS2 type of RS; starch granules are inaccessible to amylases due to granule starch structure ${ }^{(43)}$. In line with other recent pig studies ${ }^{(14,47)}$ where retrograded tapioca starch was applied as the RS source (RS3 type), we found that RS was mainly degraded in the caecum. The higher proportion of $\mathrm{RS}_{\mathrm{DMSO}}\left(65-100 \%\right.$ of $\left.\mathrm{RS}_{\text {enz }}\right)$ in large-intestinal digesta than in the $\mathrm{RSD}$ ( $56 \%$ of $\mathrm{RS}_{\text {enz }}$ ) indicates that the proportion of $\mathrm{RS}$ analysed as $\mathrm{RS}_{\mathrm{DMSO}}$ was more slowly fermented than the remaining $\mathrm{RS}$ in $\mathrm{RS}_{\text {enz }}$. Further analysis of individual RS ingredients (HAM-RS2 and raw potato starch) in the RSD is required to more specifically identify the origin of the $\mathrm{RS}_{\mathrm{DMSO}}$ fraction of $\mathrm{RS}_{\mathrm{enz}}$. Giuberti et al. ${ }^{(48)}$ reported that granule characteristics of potato starch differed from those of HAM-RS2 in having a larger diameter, surface area and volume, so there are likely differences in in vivo fermentability between the two RS sources. In particular, one RSD-fed pig degraded RS to a very low extent in all intestinal segments, and data from this pig were often identified as outliers in the statistical analysis and thus excluded from the dataset. A large individual difference in the ability of the microbiota to ferment RS has also been observed in human RS intervention studies ${ }^{(49)}$.

Protein sources used in the WSD and RSD were identical (wheat flour and whey protein), but the digestibility of protein was lower in all large-intestinal segments of RSD-fed pigs, probably because the fermentation of RS resulted in increased production of microbial biomass and increased secretion of endogenous proteins. In AXD-fed pigs that exhibited an even lower protein digestibility in all large-intestinal segments than in RSD-fed pigs, the same factors are believed to be responsible, with protein originating from rye flakes being more inaccessible for digestion because of structural incorporation into the cell-wall structure, as shown in previous pig studies $^{(23,50)}$. The lower digestibility of protein but also of DM corresponded well with the higher passage rate in all intestinal segments of pigs fed the high-DF diets compared with the WSD, resulting in less time for nutrient degradation and absorption. It is noteworthy that although the transit time from the small intestine to the distal colon is $28 \%$ lower in AXD-fed pigs than in RSD-fed pigs, allowing for less time for microbial fermentation of NSP components, the AXD still results in the largest SCFA pool size. It is well established that soluble DF, which is higher in the AXD than in the other two diets, reduces the digestibility of fat in the small intestine ${ }^{(51)}$. We found that this effect is persistent throughout the large intestine, similar to what has been reported in another pig study using a rye-based high-DF diet rich in $\mathrm{AX}^{(23)}$.

\section{Microbial composition and SCFA pool size}

Feeding with the AXD resulted in a higher level of not only the butyrate-producing bacteria $F$. prausnitzii, $R$. intestinalis and $B$. coccoides $-E$. rectale, but also Bifidobacterium spp. and Lactobacillus spp. in the faeces. Protein disappearance in the large intestine was similar across the diets and the $\mathrm{N}$ pool size was highest in the large intestine of AXD-fed pigs despite almost $25 \%$ less protein in the AXD than in the other two diets. Together, these results indicate that the higher number of bacteria associated with carbohydrate fermentation did not occur because of less competition from protein fermentation. In contrast, the larger pool size of BCFA in the large intestine of AXD-fed pigs (Fig. 2) indicates that feeding with the AXD actually resulted in a higher level of protein fermentation, as more protein reach the large intestine. This is supported by the results reported by Ingerslev et $a l .{ }^{(25)}$ showing that AXD-fed pigs have a significantly higher concentration of BCFA in portal blood, indicating higher BCFA absorption than that in WSD- and RSD-fed pigs. The PCA showed that $R$. intestinalis was the bacteria mostly responsible for the separation between the diets. In line with the present results, Neyrinck et al. ${ }^{(52)}$ showed that a high-fat diet with $10 \%$ long-chain soluble wheat AX increased Roseburia spp. and Bifidobacterium spp. in the caecal digesta of diet-induced obese mice compared with a control diet without AX. RS may also modify the microbial composition in the large intestine. RS from retrograded tapioca starch stimulated $F$. prausnitzii in the colon content of pigs and had a negative effect on the abundance of $R$. intestinalis and Lactobacillus ${ }^{(14)}$, whereas RS from high-amylose maize stimulated Bifidobacterium spp. in pigs ${ }^{(53)}$. Although we did not observe any changes in the microbial composition following the RSD, the degradation of NSP in the large intestine was substantially impaired in RSD-fed pigs, which indicates that the existing micro-organisms shifted towards fermenting RS instead of NSP. Since RS itself was primarily utilised in the caecum, it could positively affect colon health by delaying 
the degradation of other NSP components in the more distal parts of the large intestine.

The shift in the microbial composition of AXD-fed pigs was clearly reflected in the SCFA profile of the intestinal digesta. In general, the concentration of fermentation metabolites measured in the present study is comparable with those found in other studies with pigs fed RS- and AX-enriched $\operatorname{diets}^{(14,50)}$. Because more than $95 \%$ of the SCFA produced are rapidly absorbed from the intestinal lumen and metabolised by the host, SCFA production would be more precisely estimated if the luminal SCFA pool was coupled to the quantitative measurements of SCFA in portal blood ${ }^{(54)}$. By using the same experimental diets as applied in the present study, Ingerslev et al. ${ }^{(25)}$ showed that the AXD most efficiently stimulated the absorption of total SCFA and butyrate in the portal blood of multi-catheterised pigs, followed by the RSD and then by the WSD. Based on their results, it seems reasonable that we use the pool of total and individual SCFA in intestinal segments to estimate the daily production of SCFA. In accordance with the results from other studies in pigs $^{(55-57)}$, we found that the SCFA pool size was low in the distal small intestine, increased in the caecum, peaked in the proximal colon and then declined towards the distal colon. This profile is consistent with greater fermentation of non-digestible carbohydrates occurring in the proximal large intestine (through greater substrate availability) and a decline in the pool size due to the depletion of the substrate and the absorption of SCFA from the digesta to the portal blood.

AX most efficiently increased both butyrate concentration and pool size in the caecum, proximal and mid part of the colon compared with RS. A number of in vitro studies have compared the concentration of SCFA following inoculation of different types of DF with human faeces ${ }^{(58,59)}$ or in in vitro human gut simulation models ${ }^{(60)}$. However, only one study has compared the effects of human faecal inoculation with high-amylose maize RS or maize bran AX for $12 \mathrm{~h}$ of incubation and found no difference in butyrate production between the two substrates ${ }^{(58)}$. Typical for these in vitro models is that they do not account for the dynamics of SCFA absorption in the intestinal epithelium and that the microbial community has a very short adaptation time to the introduced substrates compared with the present study on pig microbiota conducted during an experimental period of 3 weeks, which makes SCFA concentrations difficult to compare.

\section{Conclusion}

In the present study, we report that DF provided as either RS type 2 from high-amylose maize and raw potato starch or AX from rye flakes and enzyme-treated wheat bran has a significant and different influence on digestion processes and on the digestibility of nutrients and NSP components in the large intestine compared with a Western-style control diet low in DF. An AX-rich diet is more efficient than a RS-rich diet in shifting the microbial composition towards butyrogenic species in the faeces and in increasing the pool size of total SCFA and butyrate concentrations in the caecum, proximal and mid colon and in the entire large intestine.

\section{Acknowledgements}

The authors thank Winnie Østergaard, Lisbeth Märcher, Kasper Bøgild Poulsen, Henri Ahokoski and Thomas Rebsdorf for excellent technical assistance. The authors acknowledge Lantmännen Cerealia A/S for providing rye flakes, and KMC Amba for providing the raw potato starch. The authors also acknowledge Mads Brøgger Pedersen for assistance in the PCA. The study was financially supported by the Danish Strategic Research Council, project 'Concepts for enhanced butyrate production to improve colonic health and insulin sensitivity' (project no. 10-093526). The Danish Strategic Research Council had no role in the design and analysis of the study or in the preparation of this manuscript.

The authors' contributions are as follows: K. E. B. K., H. N. L. and P. K. T. were responsible for project development; T. S. N., P. K. T. conducted the animal experiment; M. S. and S. F. carried out the microbial composition analysis; T. S. N. performed the statistical analysis and drafted the manuscript; J. F. S. produced the enzymatically modified wheat bran. All authors contributed, commented and approved the final content of the manuscript.

There are no conflicts of interest.

\section{References}

1. Lipkin M, Reddy B, Newmark H, et al. (1999) Dietary factors in human colorectal cancer. Annu Rev Nutr 19, 545-586.

2. Spooren CE, Pierik MJ, Zeegers MP, et al. (2013) Review Article: the association of diet with onset and relapse in patients with inflammatory bowel disease. Aliment Pharmacol Ther 38, 1172-1187.

3. Wong JM, de Souza R, Kendall CW, et al. (2006) Colonic health: fermentation and short chain fatty acids. $J$ Clin Gastroenterol 40, 235-243.

4. Leonel AJ \& Alvarez-Leite JI (2012) Butyrate: implications for intestinal function. Curr Opin Clin Nutr Metab Care 15, 474-479.

5. Perrin P, Pierre F, Patry Y, et al. (2001) Only fibres promoting a stable butyrate producing colonic ecosystem decrease the rate of aberrant crypt foci in rats. Gut $\mathbf{4 8}, 53-61$.

6. Toden S, Bird AR, Topping DL, et al. (2007) Dose-dependent reduction of dietary protein-induced colonocyte DNA damage by resistant starch in rats correlates more highly with caecal butyrate than with other short chain fatty acids. Cancer Biol Ther 6, 253-258.

7. Kovarik JJ, Tillinger W, Hofer J, et al. (2011) Impaired antiinflammatory efficacy of $n$-butyrate in patients with IBD. Eur J Clin Invest 41, 291-298.

8. Hamer HM, Jonkers DM, Bast A, et al. (2009) Butyrate modulates oxidative stress in the colonic mucosa of healthy humans. Clin Nutr 28, 88-93.

9. Clarke JM, Young GP, Topping DL, et al. (2012) Butyrate delivered by butyrylated starch increases distal colonic epithelial apoptosis in carcinogen-treated rats. Carcinogenesis 33, 197-202.

10. Canani RB, Di Costanzo M \& Leone L (2012) The epigenetic effects of butyrate: potential therapeutic implications for clinical practice. Clin Epigenetics $\mathbf{4}, 4$.

11. Fung KY, Cosgrove L, Lockett T, et al. (2012) A review of the potential mechanisms for the lowering of colorectal oncogenesis by butyrate. BrJ Nutr 108, 820-831. 
12. The European Commission (2008) EU and Codex Definitions of dietary fibre - text with comments by N.G. Asp and S. Bryngelsson. http://www.healthgrain.org/webfm_send/48 (accessed March 2014).

13. Bird AR, Conlon MA, Christophersen CT, et al. (2010) Resistant starch, large bowel fermentation and a broader perspective of prebiotics and probiotics. Benef Microbes $\mathbf{1}$, 423-431.

14. Haenen D, Zhang J, Souza da Silva C, et al. (2013) A diet high in resistant starch modulates microbiota composition, SCFA concentrations, and gene expression in pig intestine. J Nutr 143, 274-283.

15. Hamer HM, Jonkers D, Venema K, et al. (2008) Review Article: the role of butyrate on colonic function. Aliment Pharmacol Ther 27, 104-119.

16. Jackson-Thompson J, Ahmed F, German RR, et al. (2006) Descriptive epidemiology of colorectal cancer in the United States, 1998-2001. Cancer 107, 1103-1111.

17. Kolida S, Tuohy K \& Gibson GR (2002) Prebiotic effects of inulin and oligofructose. Br J Nutr 87, Suppl. 2, S193-S197.

18. Izydorczyk MS \& Biliaderis CG (1995) Cereal arabinoxylans: advances in structure and physicochemical properties. Carbohydr Polym 28, 33-48.

19. Glitso LV, Gruppen H, Schols HA, et al. (1999) Degradation of rye arabinoxylans in the large intestine of pigs. J Sci Food Agric 79, 961-969.

20. Nielsen KL, Hartvigsen ML, Hedemann MS, et al. (2014) Similar metabolic responses in pigs and humans to breads with different contents and compositions of dietary fibers: a metabolomics study. Am J Clin Nutr 99, 941-949.

21. Miller ER \& Ullrey DE (1987) The pig as a model for human nutrition. Annu Rev Nutr 7, 361-382.

22. Damen B, Cloetens L, Broekaert WF, et al. (2012) Consumption of breads containing in situ-produced arabinoxylan oligosaccharides alters gastrointestinal effects in healthy volunteers. J Nutr 142, 470-477.

23. Bach Knudsen KE, Serena A, Kjaer AK, et al. (2005) Rye bread enhances the production and plasma concentration of butyrate but not the plasma concentrations of glucose and insulin in pigs. $J$ Nutr 135, 1696-1704.

24. Choct M, Selby EAD, Cadogan DJ, et al. (2004) Effects of particle size, processing, and dry or liquid feeding on performance of piglets. Aust J Agric Res 55, 237-245.

25. Ingerslev AK, Theil PK, Hedemann MS, et al. (2014) Resistant starch and arabinoxylan augment SCFA absorption, but affect postprandial glucose and insulin responses differently. Br J Nutr 111, 1564-1576.

26. AOAC (1990) Official Methods of Analysis of $A O A C$ International, 15th ed. Arlington, VA: AOAC International.

27. Hansen B (1989) Determination of nitrogen as elementary N, and alternative to Kjeldahl. Acta Agric Scand 39, 113-118.

28. Stoldt W (1952) Worslag zur verinheitlichung der fettbestimmung in lebensmitteln (Suggestion to standardise the determination of fat in foodstuffs). F Seif Anst $\mathbf{5 4}$, 206-207.

29. Larsson K \& Bengtsson S (1983) Bestämning av lätttilgängeliga kolhydrater $\mathrm{i}$ växtmaterial (Determination of readily available carbohydrates in plant material). In National Laboratory of Agricultural Chemistry Methods Report no. 22, vol. 22, Uppsala: National Laboratory of Agricultural Chemistry.

30. Bach Knudsen KE (1997) Carbohydrate and lignin contents of plant materials used in animal feeding. Anim Feed Sci Technol 67, 319-338.

31. Kasprzak MM, Lærke HN \& Bach Knudsen KE (2012) Effects of isolated and complex dietary fiber matrices in breads on carbohydrate digestibility and physiochemical properties of ileal effluent from pigs. J Agric Food Chem 60, 12469-12476.

32. Englyst HN \& Cummings JH (1984) Simplified method for the measurement of total non-starch polysaccharides by gas-liquid-chromatography of constitute sugars as alditol acetate. Analyst 109, 937-942.

33. Theander O \& Åman P (1979) Studies on dietary-fibers. 1. Analysis and chemical characterization of water-soluble and water-insoluble dietary-fibers. Swe J Agric Res 9, 97-106.

34. McCleary BV \& Glennie-Holmes M (1985) Enzymatic quantification of $(1 \rightarrow 3)(1 \rightarrow 4)-\beta$-D-glucan in barley and malt. J Inst Brew 91, 285-295.

35. Schürch AF, Lloyd LE \& Crampton EW (1950) The use of chromic oxide as an index for determining digestibility of a diet. J Nutr 41, 629-636.

36. Jensen MT, Cox RP \& Jensen BB (1995) Microbial production of skatole in the hindgut of pigs given different diets and its relation to skatole deposition in the back fat. Anim Sci $\mathbf{6 1}$, 293-304.

37. Lahtinen SJ, Forssten S, Aakko J, et al. (2012) Probiotic cheese containing Lactobacillus rhamnosus HNO01 and Lactobacillus acidophilus NCFM(R) modifies subpopulations of fecal lactobacilli and Clostridium difficile in the elderly. Age (Dordr) 34, 133-143.

38. Rinttila T, Kassinen A, Malinen E, et al. (2004) Development of an extensive set of $16 \mathrm{~S}$ rDNA-targeted primers for quantification of pathogenic and indigenous bacteria in faecal samples by real-time PCR. J Appl Microbiol 97, 1166-1177.

39. Makivuokko $H$, Nurmi J, Nurminen $P$, et al. (2005) In vitro effects on polydextrose by colonic bacteria and caco-2 cell cyclooxygenase gene expression. Nutr Cancer 52, 94-104.

40. Russell WR, Hoyles L, Flint HJ, et al. (2013) Colonic bacterial metabolites and human health. Curr Opin Microbiol 16, 246-254.

41. Brahe LK, Astrup A \& Larsen LH (2013) Is butyrate the link between diet, intestinal microbiota and obesity-related metabolic diseases? Obes Rev 14, 950-959.

42. Bach Knudsen KE \& Lærke HN (2010) Rye arabinoxylans: molecular structure, physiochemical properties and physiological effects in the gastrointestinal tract. Cereal Chem $\mathbf{8 7}$, 353-362.

43. Annison G \& Topping DL (1994) Nutritional role of resistant starch: chemical structure vs physiological function. Annu Rev Nutr 14, 297-320.

44. Glitso LV, Brunsgaard G, Hojsgaard S, et al. (1998) Intestinal degradation in pigs of rye dietary fibre with different structural characteristics. Br J Nutr 80, 457-468.

45. Rose DJ, Patterson JA \& Hamaker BR (2010) Structural differences among alkali-soluble arabinoxylans from maize (Zea mays), rice (Oryza sativa), and wheat (Triticum aestivum) brans influence human fecal fermentation profiles. J Agric Food Chem 58, 493-499.

46. Higgins JA \& Brown IL (2013) Resistant starch: a promising dietary agent for the prevention/treatment of inflammatory bowel disease and bowel cancer. Curr Opin Gastroenterol 29, 190-194.

47. Jonathan MC, Haenen D, Souza da Silva C, et al. (2013) Influence of a diet rich in resistant starch on the degradation of non-starch polysaccharides in the large intestine of pigs. Carbohydr Polym 93, 232-239.

48. Giuberti G, Gallo A, Moschini M, et al. (2013) In vitro production of short-chain fatty acids from resistant starch by pig faecal inoculum. Animal 7, 1446-1453.

49. McOrist AL, Miller RB, Bird AR, et al. (2011) Fecal butyrate levels vary widely among individuals but are usually 
increased by a diet high in resistant starch. J Nutr 141, 883-889.

50. Le Gall M, Serena A, Jorgensen H, et al. (2009) The role of whole-wheat grain and wheat and rye ingredients on the digestion and fermentation processes in the gut - a model experiment with pigs. Br J Nutr 102, 1590-1600.

51. Johnson IT (1992) The influence of dietary fibre on lipid digestion and absorption. In Dietary Fibre - A Component of Food. Nutritional Function in Health and Disease, pp. 167-180. New York, NY: Springer.

52. Neyrinck AM, Possemiers S, Druart C, et al. (2011) Prebiotic effects of wheat arabinoxylan related to the increase in bifidobacteria, Roseburia and Bacteroides/Prevotella in diet-induced obese mice. PLOS ONE 6, e20944.

53. Regmi PR, Metzler-Zebeli BU, Ganzle MG, et al. (2011) Starch with high amylose content and low in vitro digestibility increases intestinal nutrient flow and microbial fermentation and selectively promotes bifidobacteria in pigs. J Nutr 141, 1273-1280.

54. Theil PK, Jorgensen H, Serena A, et al. (2011) Products deriving from microbial fermentation are linked to insulinaemic response in pigs fed breads prepared from whole-wheat grain and wheat and rye ingredients. Br J Nutr 105, $373-383$.
55. Bach Knudsen KE \& Hansen I (1991) Gastrointestinal implications in pigs of wheat and oat fractions. 1. Digestibility and bulking properties of polysaccharides and other major constituents. Br J Nutr 65, 217-232.

56. Marsono Y, Illman RJ, Clarke JM, et al. (1993) Plasma lipids and large bowel volatile fatty acids in pigs fed on white rice, brown rice and rice bran. Br J Nutr 70, 503-513.

57. Govers MJ, Gannon NJ, Dunshea FR, et al. (1999) Wheat bran affects the site of fermentation of resistant starch and luminal indexes related to colon cancer risk: a study in pigs. Gut 45, 840-847.

58. Yang J, Martinez I, Walter J, et al. (2013) In vitro characterization of the impact of selected dietary fibers on fecal microbiota composition and short chain fatty acid production. Anaerobe 23, 74-81.

59. Kaur A, Rose DJ, Rumpagaporn $P$, et al. (2011) In vitro batch fecal fermentation comparison of gas and short-chain fatty acid production using "slowly fermentable" dietary fibers. J Food Sci 76, H137-H142.

60. van den Abbeele P, Venema K, Van De Wiele T, et al. (2013) Different human gut models reveal the distinct fermentation patters of arabinoxylan versus inulin. J Agric Food Chem $\mathbf{6 1}$, 9819-9827. 